Article

\title{
High Accuracy Buoyancy for Underwater Gliders: The Uncertainty in the Depth Control ${ }^{\dagger}$
}

\author{
Enrico Petritoli, Fabio Leccese *(D) and Marco Cagnetti \\ Science Department, Università degli Studi “Roma Tre", Via della Vasca Navale n. 84, 00146 Rome, Italy; \\ e_petritoli@libero.it (E.P.); ing.marco.cagnetti@gmail.com (M.C.) \\ * Correspondence: fabio.leccese@uniroma3.it; Tel.: +39-06-5733-7347 \\ † This paper is an extended version of our paper published in Petritoli, E.; Leccese, F; Cagnetti, M. A High \\ Accuracy Buoyancy System Control for an Underwater Glider. In Proceedings of the second IEEE \\ International Workshop on Metrology for the Sea (MetroSea), Bari, Italy, 8-10 October 2018.
}

Received: 8 March 2019; Accepted: 12 April 2019; Published: 17 April 2019

\begin{abstract}
This paper is a section of several preliminary studies of the Underwater Drones Group of the Università degli Studi "Roma Tre" Science Department: We describe the study philosophy, the theoretical technological considerations for sizing and the development of a technological demonstrator of a high accuracy buoyancy and depth control. We develop the main requirements and the boundary conditions that design the buoyancy system and develop the mathematical conditions that define the main parameters.
\end{abstract}

Keywords: uncertainty; buoyancy; depth control; accuracy; AUV; glider; autonomous; underwater; vehicle

\section{Introduction}

This paper is part of several preliminary studies by Underwater Drones Group (UDG) of the Science Department of the Università degli Studi "Roma Tre", which is developing an advanced Autonomous Underwater Vehicle (AUV) for the exploration of the sea at high depths. The final aim of the project is to create a platform for underwater scientific research that can accommodate a wide range of different payloads.

We will examine the buoyancy system and evaluate its sizing; then we will illustrate the technological solution we have come up with in order to realize the hydraulic system to be assembled in the Underwater Glider Mk. III (see Figure 1) [1-5].

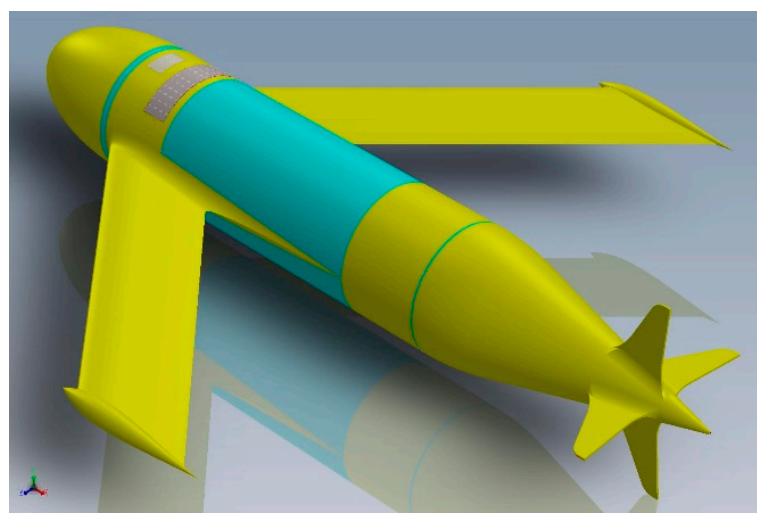

(a)

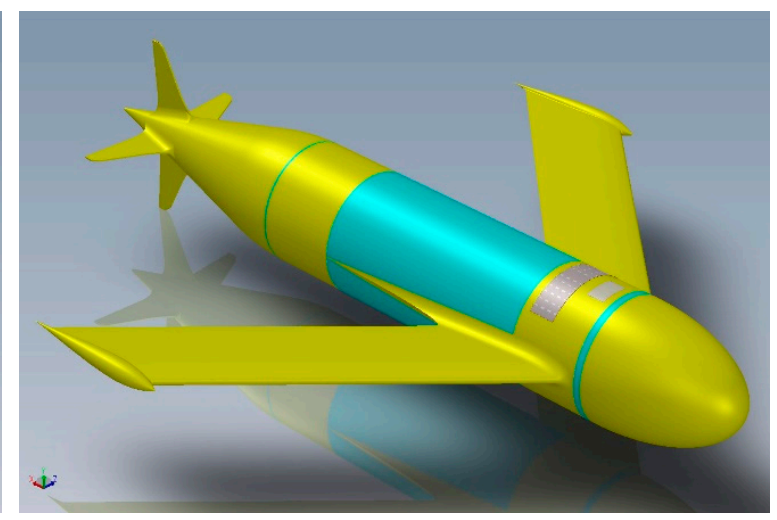

(b)

Figure 1. Perspective view of the Underwater Glider Mk. III. (a) Rear/port; (b) front/starboard. 


\subsection{The Underwater Glider}

\subsubsection{AUV Evolution}

The exploration of the underwater world has always been one of mankind's dreams: submarines and bathyscaphes (for extreme depths) have been developed to study the "deep blue". Due to obvious dangers, the human exploration can take place only for very short periods and very limited areas: for these reasons, the exploration of the sea has immediately been drawn towards unmanned automatic systems [6-8].

An AUV is a vehicle that travels underwater without requiring input from an operator; this means that it must be equipped with a "brain" that regulates and coordinates its position, its depth and its speed: moreover, it is able to collect and store data from the payload. One of the first realizations was the Autonomous LAgrangian Circulation Explorer (ALACE) system, a buoy that was able to vary its buoyancy and therefore its depth. Although it possessed a great endurance, it only could be employed for great depths and in open sea-the consequences of these limitations are evident.

The next step was the use of Remote Operated Vehicles (ROVs). These, thanks to the constant development of electronic miniaturization, are extremely high performing vehicles for short-lasting marine operations, but the require the constant presence of a support vessel.

The need to get rid of the randomness of the currents has led to the natural development of the underwater glider concept [9-15].

\subsubsection{The Underwater Glider}

An underwater glider is a vehicle that, by changing its buoyancy, moves up and down in the ocean like a profiling float [16]. It uses hydrodynamic wings to convert vertical motion into horizontal motion, moving forward with very low power consumption [17-22]. While not as fast as conventional AUVs, the glider, using buoyancy-based propulsion, offers increased range and endurance compared to motor-driven vehicles and missions may extend to months and to several thousands of kilometres in range. An underwater glider follows an up-and-down, sawtooth-like mission profile providing data on temporal and spatial scales unavailable with previous types of AUVs [23-27].

\subsubsection{The Mk. III Architecture}

The Mk. III sub-glider has a cylindrical fuselage with a radome on the bow containing the customizable payload and, on the other end, the hydrodynamic fairing. The vehicle does not have moving surfaces: control is provided by the displacement of the battery package that varies the position of the centre of mass. The wings aerofoil is based on the Eppler E838 Hydrofoil. The aerofoil has the maximum thickness $18.4 \%$ at $37.2 \%$ chord and maximum camber $0 \%$ at $46.5 \%$ chord. The arrangement of the internal sectors is visible in Figure 2a,b. The buoyancy system is contained in the buoyancy control bay: it accommodates the buoyancy motor and the oil tank and provides longitudinal balance to the system by adjusting the level in the reservoir. The bladder is contained in the hydrodynamic fairing, in contact with the open water. The fairing is not a critical structural part-it has the task of not disturbing the hydrodynamic flow of the fuselage [28].

\subsubsection{Conventions}

We introduce, for clarity, the mathematical conventions and symbols that will be used in the subsequent discussion (see Figure 3a,b): where:

- $\quad \alpha($ or $\varphi)$ is the angle between the $x$ axis and the $N$ axis.

- $\quad \beta($ or $\theta$ ) is the angle between the $z$ axis and the $Z$ axis.

- $\gamma($ or $\psi)$ is the angle between the $N$ axis and the $X$ axis. 
For the rotation matrix, we have:

$$
\boldsymbol{R}=\left(\begin{array}{ccc}
0 & -\zeta_{z} & \zeta_{y} \\
\zeta_{z} & 0 & -\zeta_{x} \\
-\zeta_{y} & \zeta_{x} & 0
\end{array}\right)
$$

where $\zeta$ is the parameter vector [29].

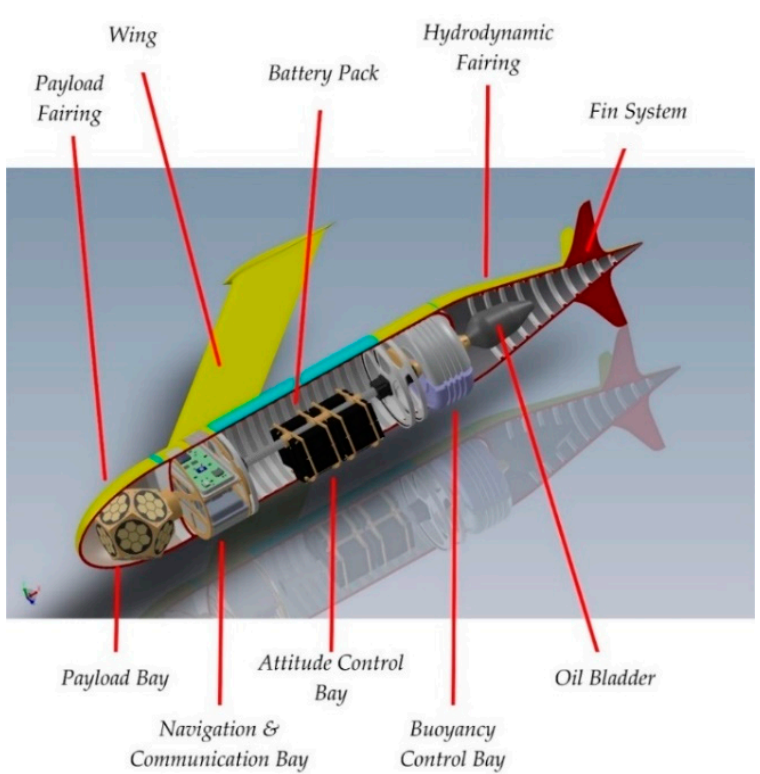

(a)

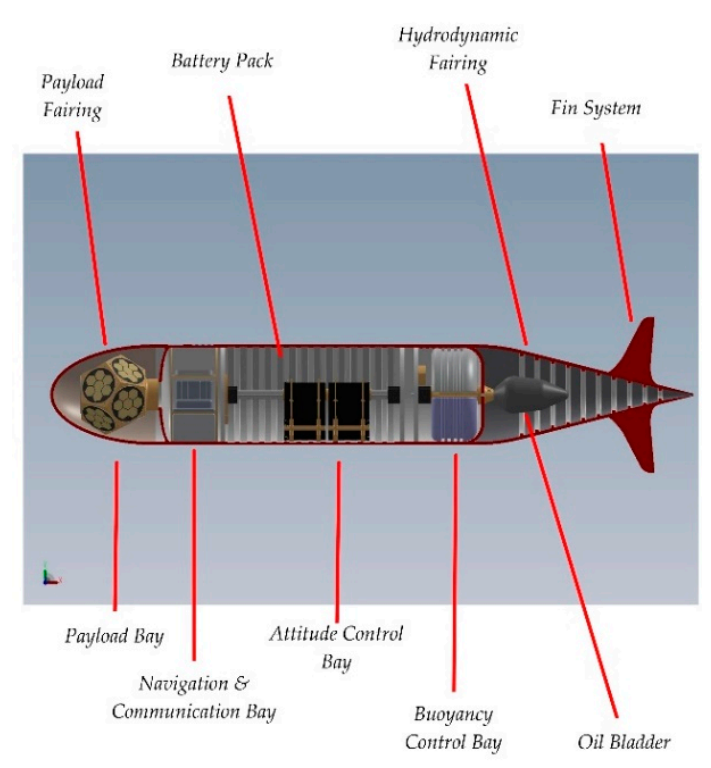

(b)

Figure 2. Underwater Glider Mk. III cutaway: (a) fuselage prospective section; (b) fuselage sagittal section.

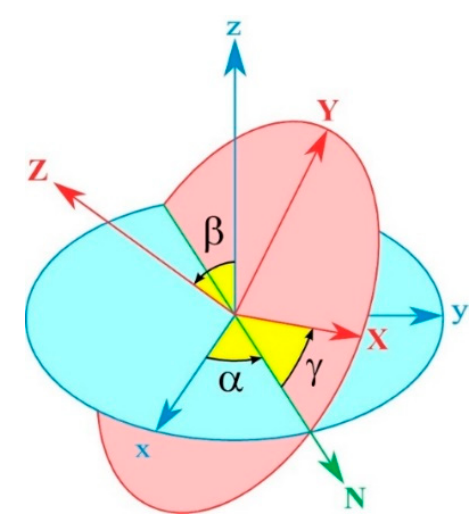

(a)

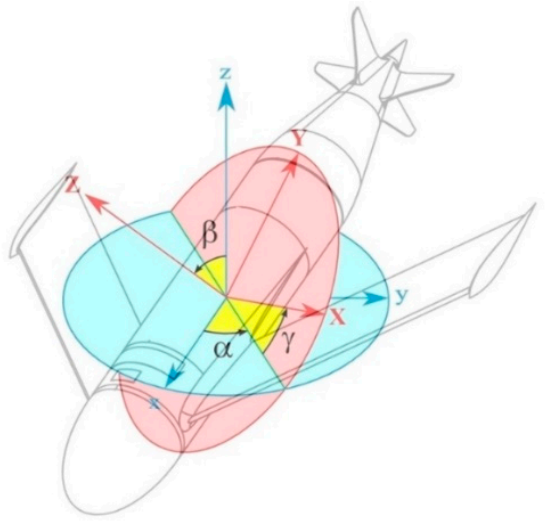

(b)

Figure 3. The Euler angles. (a) Body frame (blue) and reference frame (red); (b) The body frame referred to the drone.

\section{Materials and Methods}

\subsection{The Buoyancy System}

\subsubsection{Basic Concepts}

Gliders are controlled through hydrostatics (vertical forces) and manipulate hydrostatic balances in order to accomplish roll and pitch of the vehicle. Stability of the vehicle is a major critical factor: 
a stable vehicle has the centre of gravity below the centre of buoyancy. In this configuration, the weight of the vehicle creates a restoring moment to add stability to the vehicle. Roll and pitch on the glider is accomplished by moving the battery pack. Figure 4 below displays a basic concept of a buoyancy system for the glider [30-36].

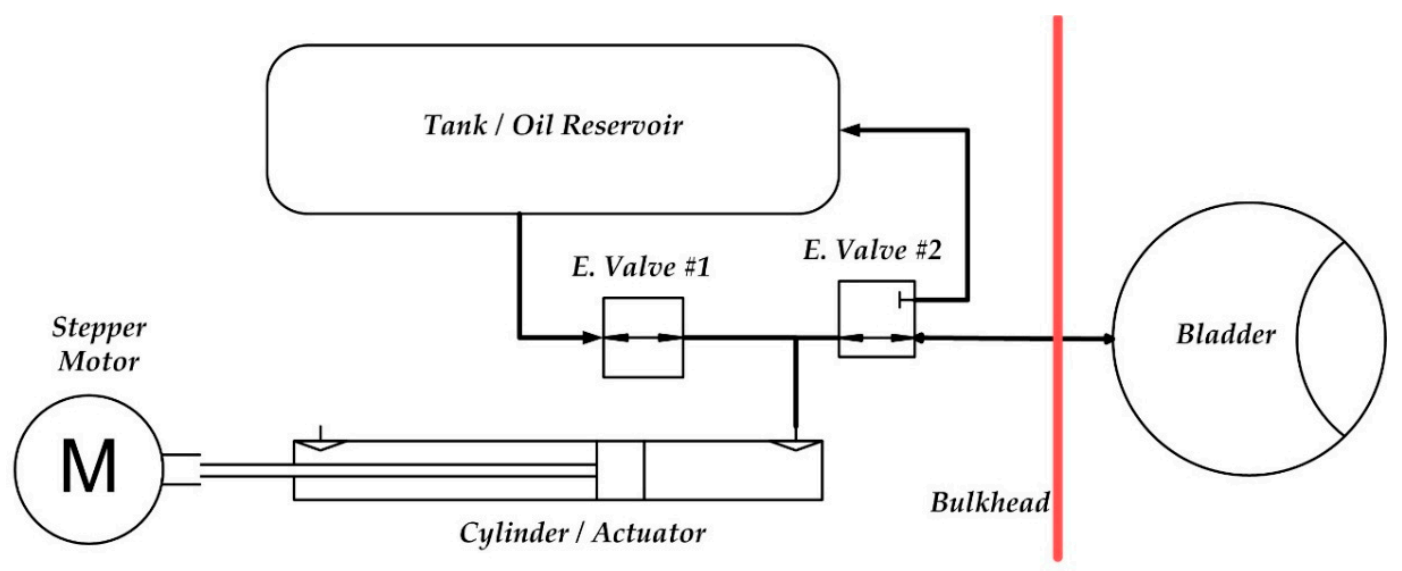

Figure 4. Basic scheme of the buoyancy system.

The system is extremely simple: while descending, hydraulic fluid moves from the external inflatable bladder, which produces a high pressure in the internal reservoir, which is at a low pressure through a valve: the decrease in volume of the bladder creates an increase in density, causing negative buoyancy [37-44].

While ascending, hydraulic fluid moves from internal accumulator to the external inflatable bladder through the pump. The increase in volume creates a decrease in density causing positive buoyancy. The seawater also flushes out the open hydrodynamic fairing of the vehicle, aiding it to rise to the surface. For neutral buoyancy, the vehicle must have a density equal to seawater [45-52].

\subsubsection{The System Prototype}

Our group has developed a technology demonstrator (see Figure 4) of the buoyancy system to validate the related technology and then to test it. To reduce the force required to actuate the oil piston, which pushes the oil in the bladder at high pressure, is necessary to reduce the piston surface (diameter) and increase the stroke: so, the buoyancy engine resembles a "shotgun". An open-loop stepper motor was used to drive the screw inside the actuator that, in turn, pushes the piston. Two solenoid valves regulate the flow of oil into the bladder [53-57].

The first problem was the occurrence of actuator buckling: under the push of the engine, the probability of a part bending is high, thus deforming the thread and jamming the mechanism. The problem was solved by constructing a rigid cage with four struts that support the piston's push load, leaving the screw only with the rolling friction load. In the early project development stages, the workgroup was oriented to use a centrifugal pump for all drives: this technology however did not allow us to create strong pressure differences; the need to use a more powerful engine was also highlighted because the prevalence was too low: this would have led to an excessive battery consumption. The second solution was to use volumetric pumps in order to obtain greater differences in pressure (even ones considerably higher than needed). Unfortunately, these would require too much power and are too heavy for our small vehicle [58-62].

At this stage of development, we have also thought to use the oil tank only as a passive fluid reservoir and trimmable counterweight of the payload and as an active actuator for longitudinal stability. The long travel of the piston (forward or backward) ensures the necessary variation of the bladder volume for manoeuvrability [63]. 
Now, the system prototype seems to work correctly and promises new developments: it is under in several fatigue cycle trials in order to investigate the parts more prone to failure as a sort of burn-in test. Our prototype (breadboard) is presented in Figure 5.

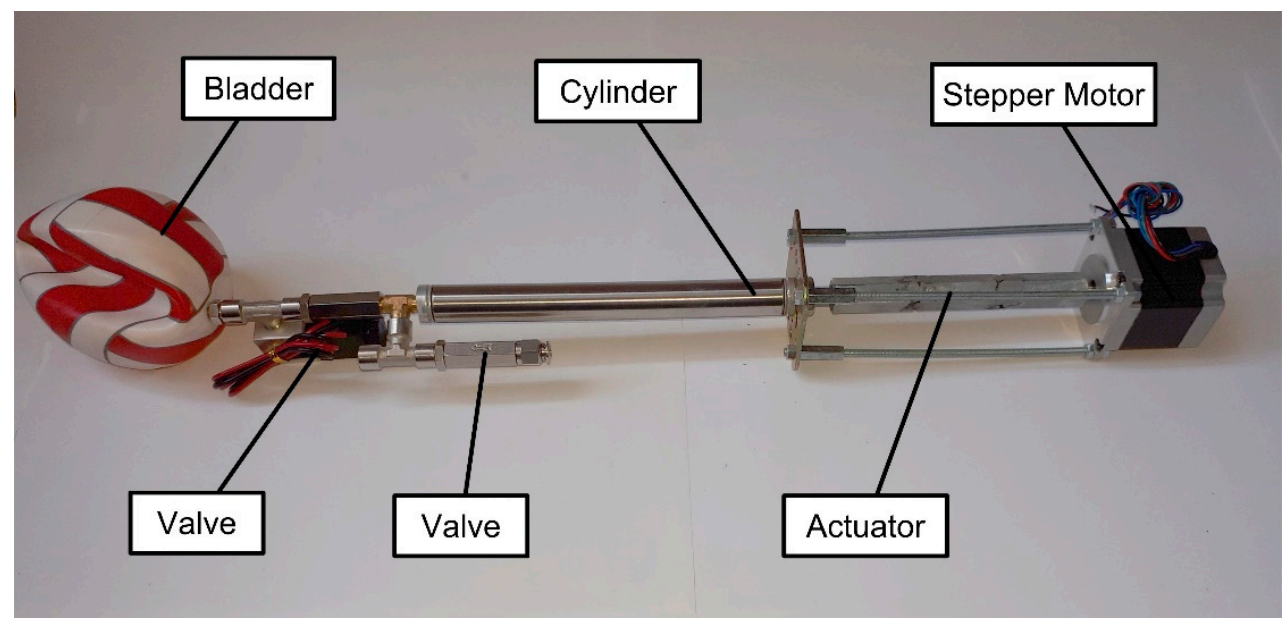

Figure 5. Buoyancy engine prototype.

\subsection{Buoyancy}

Archimedes' principle is the main concept underlying the buoyancy of underwater vehicles. When a vehicle is submerged in water, a buoyant force acts on the body vertically upward due to the pressure forces below the submerged body being greater than the pressure forces above. The buoyant force results in a value equal to the weight it displaces [64].

\subsubsection{Static Buoyancy}

Now, consider our drone (see Figure 6): it is in steady state.

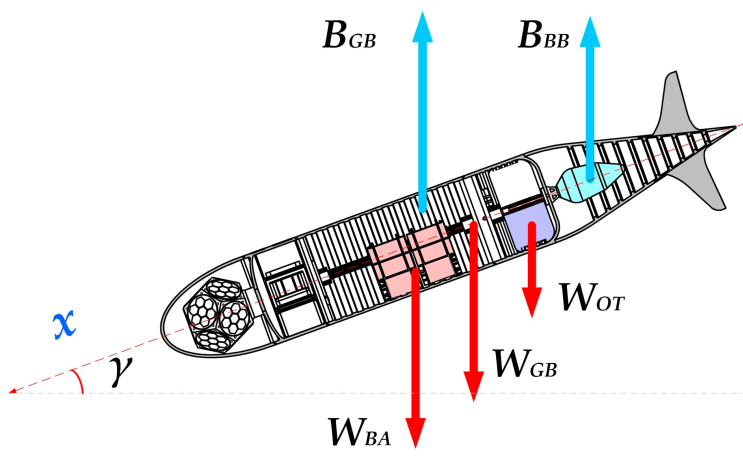

Figure 6. Drone in buoyancy Balance.

In these conditions, the total weight $W_{T O T}$ of the glider is given by:

$$
W_{T O T}=-W_{D W}+B_{G B}+B_{B B}
$$

where:

$W_{T O T}=$ Net total "weight" in the water.

$W_{D W}=$ Dry Weight of the glider.

$B_{B B}=$ Buoyancy of the oil bladder.

$B_{G B}=$ Buoyancy of the naked glider. 
The expression of dry weight is:

$$
W_{D W}=W_{B A}+W_{O T}+W_{G B}
$$

where:

$W_{B A}=$ Weight of the battery pack.

$W_{O T}=$ Weight of the oil tank.

$W_{G B}=$ Weight of the naked glider (without oil tank and batteries). For "dry weight", we mean the weight of the vehicle out of the sea, without the hydrostatic force.

So Equation (2) becomes:

$$
\sum F_{z}=W_{B A}+W_{O T}+W_{G B}+B_{G B}+B_{B B}=0
$$

This series of equations will be useful later to establish the drone descent attitude.

\subsubsection{Dynamic Balance on the Vertical Plane}

Here, the drone dive (or emersion) is examined at constant speed: it is in steady-state gliding, the geometry of total forces is explained in Figure 7a. Figure $7 \mathrm{~b}$ shows the Eppler E838 characteristic "Cl vs. Alpha (=angle of attack $\left.\alpha_{\text {att }}\right)$ ".

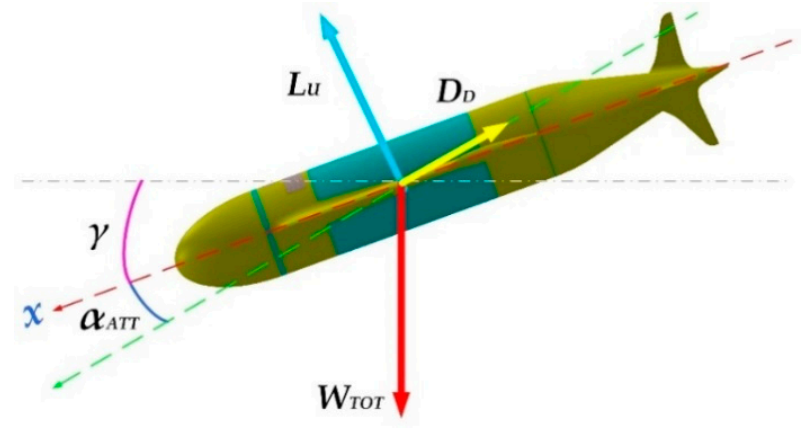

(a)

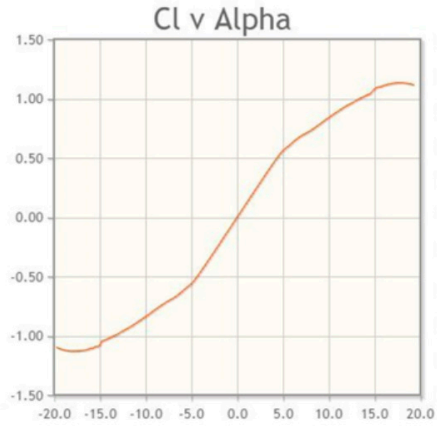

(b)

Figure 7. Dynamic balance of the forces (a) Drone geometrical balance of the forces; (b) Cl vs. Alpha (=angle of attack, $\alpha_{\text {att }}$ diagram for Eppler E838 aerofoil.

At equilibrium, for the dynamics on the vertical plane at constant speed we have:

$$
\overrightarrow{W_{T O T}}+\vec{L}+\vec{D}=0
$$

The expression for the lift is:

$$
L=\frac{1}{2} \rho v^{2} S C_{L}
$$

According to the Eppler E838 characteristic "Cl vs. Alpha" (Figure 7b) when the angle of attack $\alpha_{a t t}=0^{\circ}$ (is null) the $C_{L}$ is zero so that the lift force $L$ is null. This shows that the drone cannot progress horizontally at constant speed (straight and level): the only mission profile allowed is a sawtooth curve [65].

\subsubsection{Glider Trajectory}

Because its motion is due to the difference between the forces of weight and buoyancy, the glider is unable to proceed straight and level, thus being forced to follow a dive/climb trajectory made smooth by the wings. Moreover, unlike gliders in air, AUVs can have ascending glide slopes if the net buoyancy is positive, producing a negative sink rate. 
The buoyancy engine of the glider allows changing its net buoyancy into alternating positive and negative states, thereby imparting it with the ability to string together a succession of descending and ascending glide slopes referred to as a sawtooth glide.

The behaviour of the vehicle is considered in case of a simple glide slope (refer to Figure 7a):

$$
\begin{aligned}
\text { Lift }=\mathbb{L} & =q S C_{L} \\
\text { Drag }=\mathbb{D} & =q S C_{D} \\
\text { Pitching moment } & =\mathrm{m}=q S c C_{m}
\end{aligned}
$$

where:

$q=\frac{1}{2} \rho v^{2}:$ is the dynamic pressure.

$S:$ is the characteristic area.

$c$ : is the mean aerodynamic chord.

$\alpha_{a t t}$ : is the angle of attack.

For the other coefficients, we have:

$$
\begin{gathered}
C_{L}(\alpha)=C_{L}^{\alpha} \cdot \alpha_{a t t} \\
C_{D}(\alpha)=C_{D}^{0}+C_{D}^{\alpha} \cdot \alpha_{a t t}^{2} \\
C_{m}(\alpha)=C_{m}^{\alpha} \cdot \alpha_{a t t}
\end{gathered}
$$

The coefficient of drag $C_{D}$ is composed of two members: the first $C_{D}^{0}$ is insensitive to the angle of attack and is constant; the second one $\left(C_{D}^{\alpha} \cdot \alpha_{\text {att }}^{2}\right)$ is instead a function of the square of the angle. Note that the zero lift coefficient $C_{L}^{0}=0$ because the wing profile that has been chosen for our project is symmetrical (type Eppler 883). Now is necessary to separate the contributions of the fuselage (body) and of the wings, for the three factors of lift, friction and pitching moment; so the expression is:

$$
\left\{\begin{array}{l}
\mathbb{L}=L^{b}+L^{w} \\
\mathbb{D}=D^{b}+D^{w} \\
\mathbb{m}=m^{b}+m^{w}
\end{array}\right.
$$

According to the Navier-Stokes (approximated) equations and the simplifications above cited, the previous system of equations becomes:

$$
\left\{\begin{array}{c}
\mathbb{L}=q \sqrt{V^{3}}\left\{C_{L}^{b_{\alpha}} \cdot \alpha_{a t t}+\frac{S_{w}}{\sqrt{V^{3}}} \cdot C_{L}^{w_{\alpha}} \cdot \alpha_{a t t}\right\} \\
\mathbb{D}=q \sqrt{V^{3}}\left\{\left[C_{D}^{b_{0}}+C_{D}^{b_{\alpha}} \cdot \alpha_{a t t}^{2}\right]+\frac{S_{w w}}{\sqrt{V^{3}}}\left[C_{D}^{w_{0}}+C_{D}^{w_{\alpha}} \cdot \alpha_{a t t}^{2}\right]\right\} \\
\mathrm{m}=q \sqrt{V^{3}}\left\{C_{m}^{b_{\alpha}} \cdot \alpha_{a t t}-c_{m} \frac{l_{c b / a c w} \cdot S_{w}}{c \cdot \sqrt{V^{3}}} \cdot C_{L}^{w_{\alpha}} \cdot \alpha_{a t t}\right\}
\end{array}\right.
$$

where:

$S_{w}$ is the wing area.

$l_{c b / a c_{w}}$ is the distance between the mean aerodynamic and the center of buoyancy.

$c_{m}$ is a non-dimensional coefficient.

This parameter is necessary to know the exact attitude and therefore the $\alpha_{a t t}$ to obtain a constant descent profile [66].

\subsubsection{Gliding Forces}

In order to allow the vehicle to glide, it is necessary to create a differential buoyancy force and therefore the balance is not null: from the buoyant force expression, the change in volume needed for the buoyancy engine for a full dive is calculated as:

$$
\sum F_{Z u m b a l a n c e d}=\Delta B_{B B} \neq 0
$$


In which $\triangle B_{B B} \neq 0$ is the buoyancy force due to the difference of volume of the bladder:

$$
\sum F_{\text {Zumbalanced }}=\Delta B_{B B}=\frac{1}{2} \rho g \cdot \Delta V_{\text {bladder }}
$$

where:

$\rho=$ Seawater density (average $1.025 \mathrm{~kg} / \mathrm{l})$.

$g=$ Gravity approx. to $9.81 \mathrm{~m} / \mathrm{s}^{2}$.

$\Delta V_{\text {bladder }}=$ Volume difference of the bladder.

The relationship between difference volume of the bladder and buoyancy force is:

$$
\Delta V_{\text {bladder }}=\frac{2}{\rho g} \cdot \Delta B_{B B}
$$

2.2.5. Restoring Moment on the Vertical Plan

The position of the center of mass is given by:

$$
r_{C G}=\frac{\int r \cdot \rho(r) d V}{\int \rho(r) d V}
$$

where:

$\rho(r)$ : is the density.

$d V:$ is the considered volume.

$r$ : is the distance considered from the reference frame.

The gliders masses define above, is:

$$
r_{C G}=\frac{\sum_{i} r_{i} \cdot W_{i}}{\sum_{i} W_{i}}=\frac{r_{B A} \cdot W_{B A}+r_{O T} \cdot W_{O T}+r_{G B} \cdot W_{G B}}{W_{B A}+W_{O T}+W_{G B}}
$$

The vectorial balance of the forces becomes:

$$
\left\{\begin{array}{l}
\mathbb{F}_{\text {gravitational }}=W_{D W}\left(\boldsymbol{R}^{T} z\right) \\
\mathbb{F}_{\text {buoyancy }}=-V_{\text {Dispalacement }} \cdot g\left(\boldsymbol{R}^{T} z\right)
\end{array}\right.
$$

where

$V_{\text {Dispalacement }}$ is the volume of the drone (submerged).

$R^{T}$ is the rotation function around the reference frame.

$z$ is the upward direction.

When the geometrical centre of the body is offset from the CG frame, the resulting torque $\mathfrak{I}_{G}$ is given by:

$$
\mathfrak{I}_{G}=r_{C G} \times W_{D W}\left(\boldsymbol{R}^{T} z\right)
$$

The expression of $r_{C G}$ is:

$$
r_{C G}=\left(\begin{array}{c}
x_{C G} \\
y_{C G} \\
z_{C G}
\end{array}\right)
$$

The expression of $\hat{r}_{C G}$ is:

$$
\hat{r}_{C G}=\left(\begin{array}{ccc}
0 & -z_{C G} & y_{C G} \\
z_{C G} & 0 & -x_{C G} \\
-y_{C G} & x_{C G} & 0
\end{array}\right)
$$

Therefore, we have:

$$
\mathfrak{I}_{G}=W_{D W} \cdot \hat{r}_{C G}\left(R^{T} z\right)
$$


According to which, when the body frame is coincident with the centre of the figure:

$$
W_{D W} \cdot r_{C G}=r_{G B} \cdot B_{G B}+r_{B B} \cdot B_{B B}
$$

Moreover, the resulting balancing torque is

$$
\mathfrak{I}_{G}=\left(r_{G B} \cdot B_{G B}+r_{B B} \cdot B_{B B}\right) \cdot g\left(R^{T} z\right)
$$

This parameter is necessary to know the exact torque and therefore the position to which the servomechanism to move the battery pack will have to obtain a constant descent profile [67].

\subsubsection{Uncertainty in the Depth Control}

In this part, the problem of uncertainty in controlling the depth of the drone is examined. In the case where the drone has a very low vertical speed, due to the high viscosity of the water, the vehicle stops (and therefore stabilizes itself in the vertical plan) in a few centimeters of water, so this is not a problem.

Consider the case in which the drone is gliding, at a constant speed $\left(V_{z}<0\right)$ : at a depth of +5 m compared to the "target depth", the bladder swells up to make the drone assume a neutral buoyancy. From a dynamic point of view, our simulations show us that the drone will behave like a mass-spring-damper system, whose temporal behavior is described in Equation (23) and visible in Figure 8 (blue line).

$$
\left\{\begin{array}{c}
z_{C G}(t)=\mathbb{Z} e^{-\zeta \omega_{n} t} \cdot \cos \left(\sqrt{1-\zeta^{2}} \omega_{n} t-\Phi\right) \\
\omega_{n}=2 \pi f_{n}
\end{array}\right.
$$

The maximum precision in the measurement of depth is not given by the precision of the instrument, in this case a piezoelectric depth meter can be accurate up to $2.5 \mathrm{~cm}$, but in the architecture of the drone. Because of all the possible attitudes of the vehicle, it is not known if the transducer is placed higher or lower than the centre of gravity: so, unless more than one transducer is installed (which is impractical) the only consideration is that the maximum distance at which the transducer should be placed from the centre of gravity is precisely $49.7 \mathrm{~cm}$, so, the maximum range of precision obtainable from the instrument is:

$$
\delta_{z}=0.497 \mathrm{~m}
$$

As shown in Figure 8 (blue line) the natural dynamic stability of the vehicle, i.e., the oscillation within the error band, is obtained after a time $\mathbb{T}_{\text {normal }}=9.78 \mathrm{~s}$ which is not acceptable (see Equation (25)). It is not acceptable for two reasons: first of all because of the long damping time of the oscillation; secondly for the overshoot of the "target depth": the depth limit may have been placed not only by the type of mission but also by the nature (orography) of the seabed. Therefore, such behavior could lead to a collision of the vehicle with the seabed itself or a known obstacle, thus leading to damage:

$$
\left\{\begin{array}{c}
z_{C G}(t)_{\text {normal }} \leq \delta_{z} \\
\mathbb{T}_{\text {normal }}=9.78 \mathrm{~s}
\end{array}\right.
$$

The solution is to use the bladder as a "hydrostatic parachute" that changes the damping conditions of the system. In this case the simulation have evidenced that, if you place the bladder at maximum buoyancy (Figure 8 -red line) shortly after reaching " +5 " depth, the resulting behavior of the vehicle is visible in Figure 8 (azure line).

In this case the tolerance band is reached in $\mathbb{T}_{\text {compensated }}=4.85 \mathrm{~s}$ (see Equation (26)), half the previous time and there is no danger of overshooting the depth, thus keeping us always in safe conditions:

$$
\left\{\begin{array}{c}
z_{C G}(t)_{\text {compensated }} \leq \delta_{z} \\
\mathbb{T}_{\text {compensated }}=4.85 \mathrm{~s}
\end{array}\right.
$$


From a mathematical point of view, the system changes the damping factor, increasing it considerably in fact, $\zeta_{\text {normal }}<\zeta_{\text {compensated }}$. The model parameters are shown in Table 1 below.

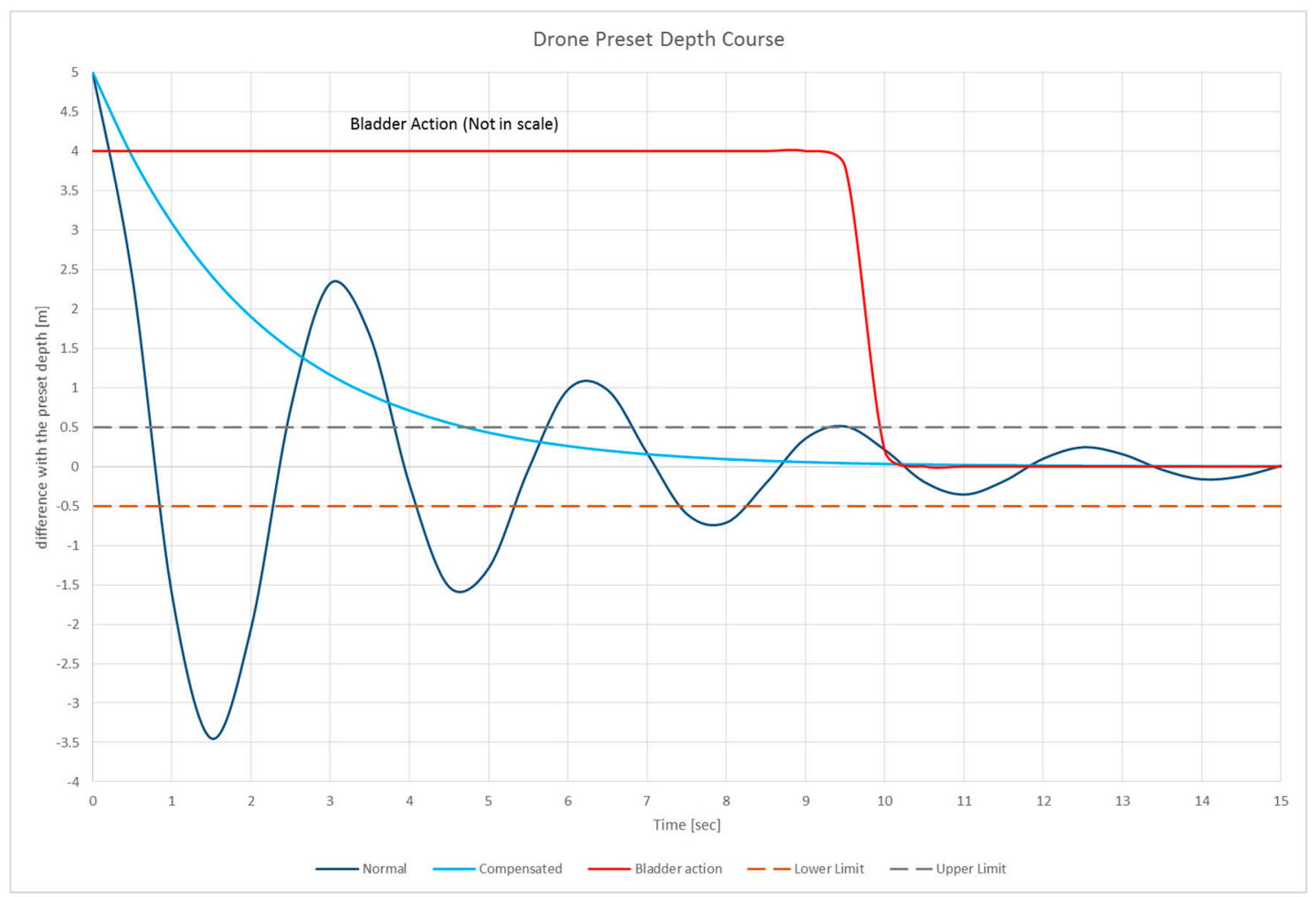

Figure 8. Drone depth dynamic behavior: in the blue line the normal (uncompensated) damping; the azure line the compensated behavior; dotted lines are the upper and lower limit. The red line (out of scale) is the bladder's "hydrostatic chute" action.

Table 1. Model parameters.

\begin{tabular}{cccc}
\hline$f_{n}$ & $\zeta_{\text {normal }}$ & $\zeta_{\text {compensated }}$ & $\mathbb{Z}$ \\
\hline 1 & 0.0794 & 0.15779 & 4.972 \\
\hline
\end{tabular}

\subsubsection{Dynamic Simulation}

In the section, we simulate the behavior of the Eppler 838 aerofoil and the fuselage to evaluate, before a detailed and expensive but more sophisticated 3D simulation, if the proportions and dimensions of the drone fall within the range of measures evaluated as a requirement. For this purpose, the program "JavaFoil-Analysis of Airfoils" [68] is used. JavaFoil is a program which uses several traditional methods for aerofoil analysis. The backbone of the program consists of two methods:

- The evaluation of the potential flow. The analysis is done with a higher order panel method (linear varying vorticity distribution) and it calculates the local, inviscid flow velocity along the surface of the aerofoil for any desired angle of attack.

- The evaluation of the boundary layer. The analysis is steps along the upper and the lower surfaces of the aerofoil, starting at the stagnation point, solves a set of differential equations to find the various boundary layer parameters, according to the integral method.

The equations and criteria for transition and separation are based on the procedures described by Eppler. A standard compressibility correction according to Karman and Tsien has been implemented to take moderate Mach number effects into account. Usually this means Mach numbers between zero and 0.5 [69-72]. 
The simulation shows the critical parameters for the hydrodynamic behaviour of the model: the results are given in Table 2 below [73-78].

Table 2. Body and wing critical parameters [Speed $=0.52 \mathrm{kts}, \mathrm{R}_{\mathrm{e}}=10^{4}$ and $\alpha_{a t t}=3.3^{\circ}$ ].

\begin{tabular}{cccccccc}
\hline$C_{L}^{b_{\alpha}}$ & $C_{L}^{w_{\alpha}}$ & $C_{D}^{b_{0}}$ & $C_{D}^{w_{0}}$ & $C_{D}^{b_{\alpha}}$ & $C_{D}^{w_{\alpha}}$ & $C_{m}^{b_{\alpha}}$ & $c_{m}$ \\
\hline 0.3997 & 0.4085 & 0.01746 & 0.01676 & 0.00018 & 0.001515 & 0.005 & 0.4752 \\
\hline
\end{tabular}

The trend of the flow lines with $\alpha_{a t t}=3.3^{\circ}$ around the body and the wing are visible in Figure 9a,b, below.

For completeness, in order to be able to express the induced resistance and the stall delay, the behavior of the aerofoil at different angles of attack is provided in Figure 10.

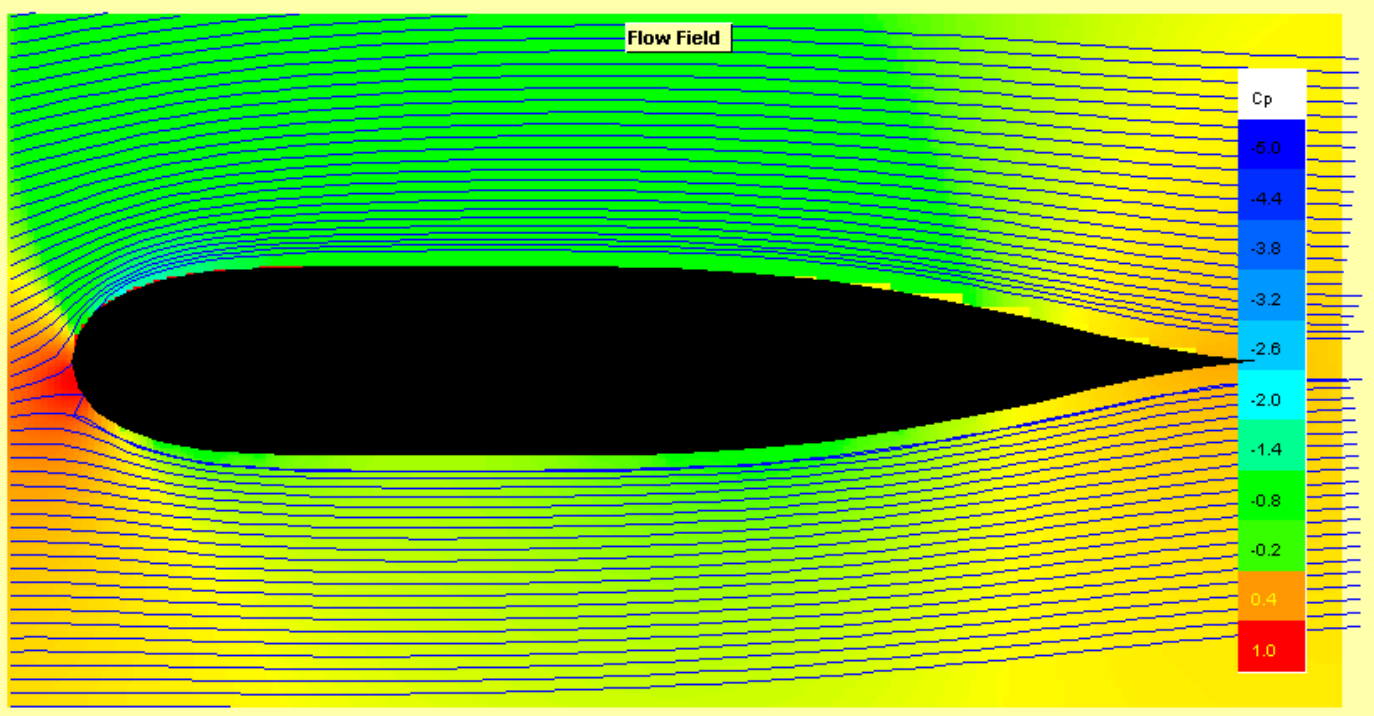

(a)

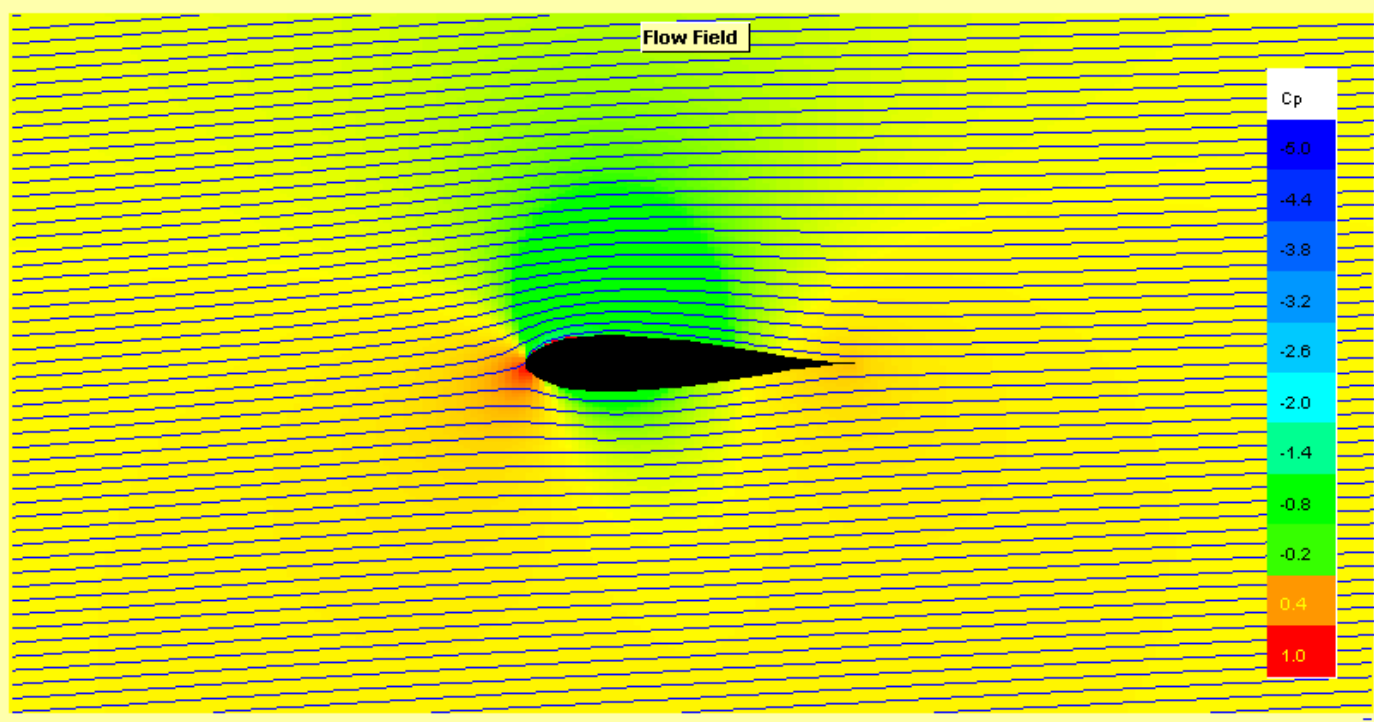

(b)

Figure 9. Flow field and pressure gradient of conditions: Speed $=0.52 \mathrm{kts}, \mathrm{R}_{\mathrm{e}}=10^{4}$ and $\alpha_{a t t}=3.3^{\circ}$, (a) Body profile of the drone; (b) Eppler 838 Aerofoil. 


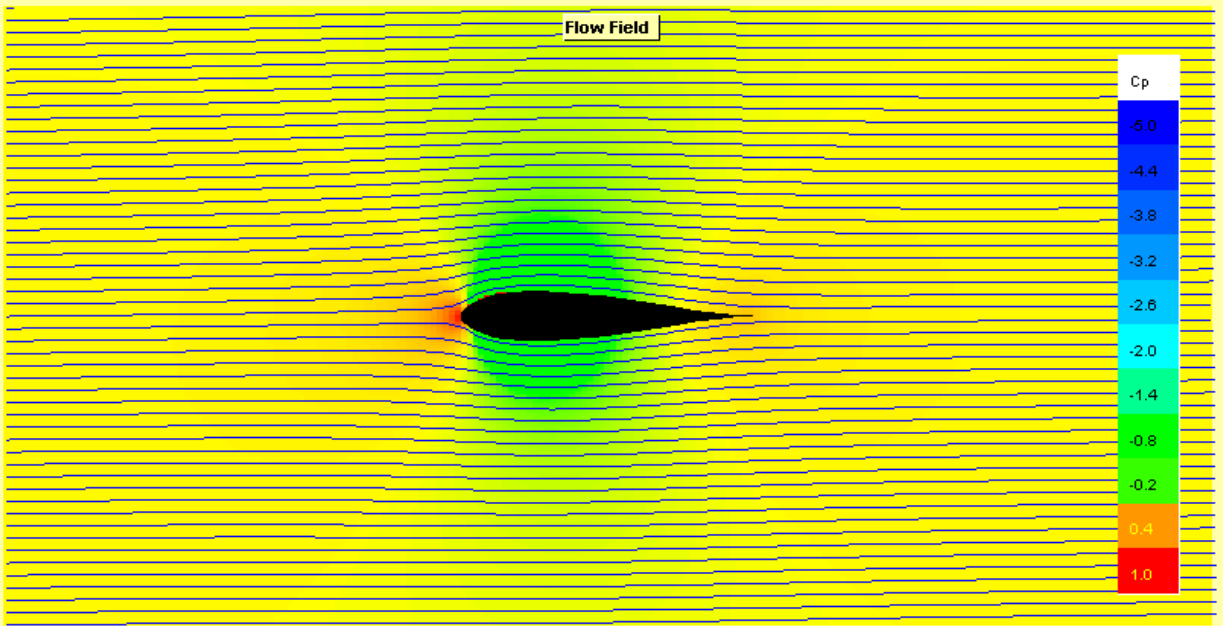

(a)

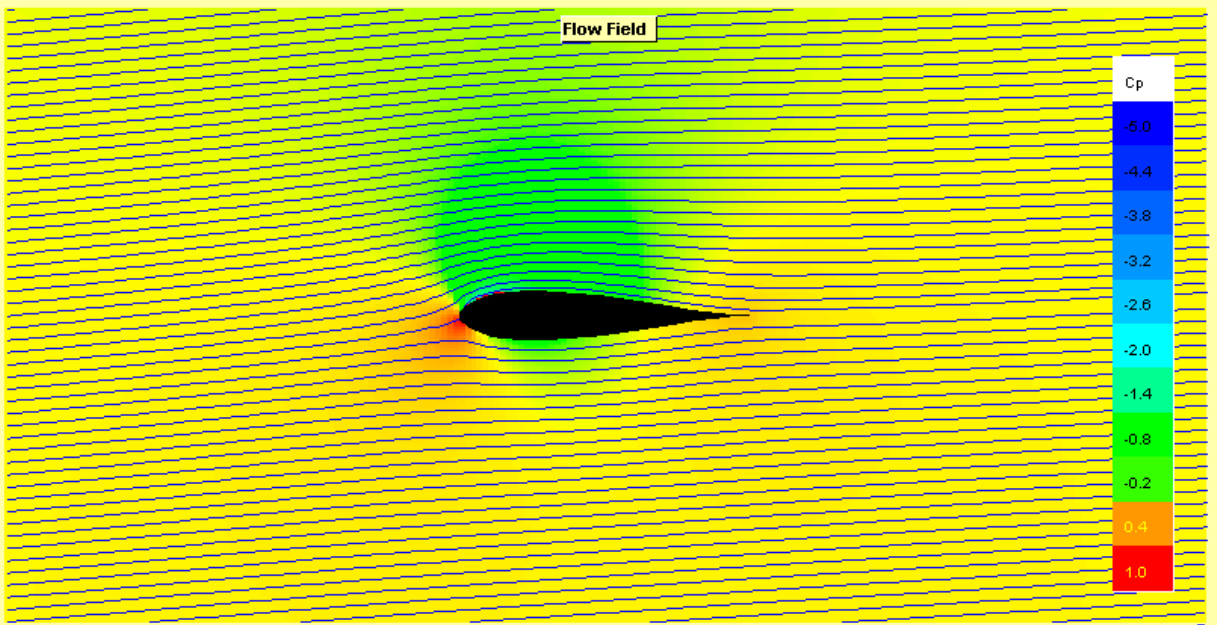

(b)

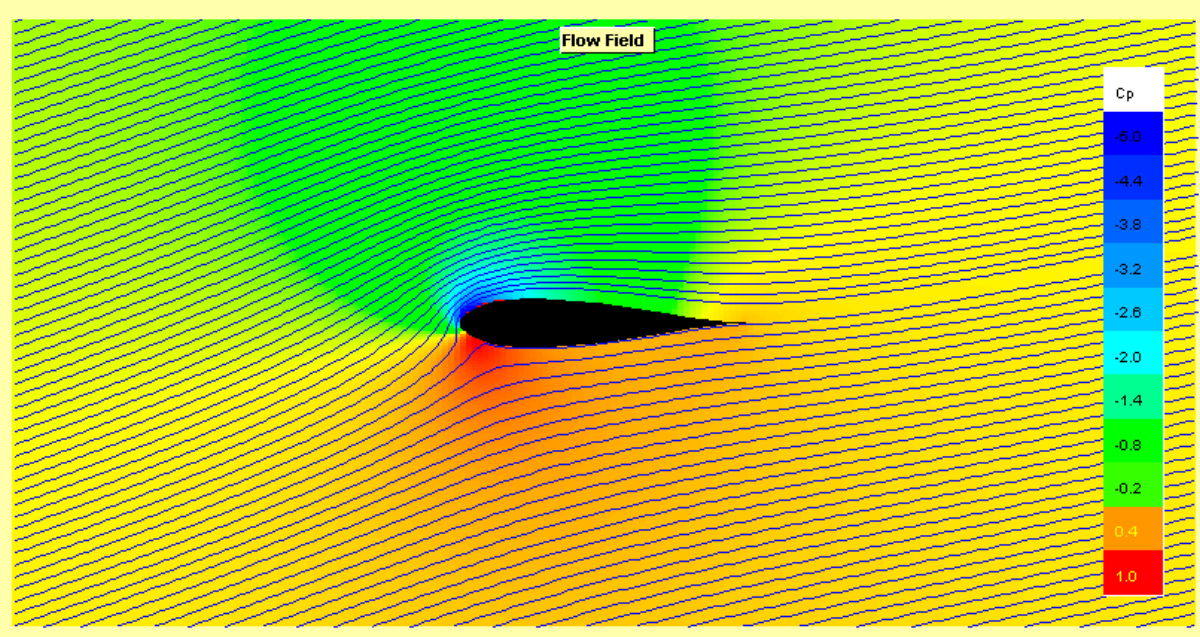

(c)

Figure 10. Flow field and pressure gradient of conditions (Speed $=0.52 \mathrm{kts}, \mathrm{R}_{\mathrm{e}}=10^{4}$ ) are shown at the following $\alpha_{\text {att }}$ : (a) $0.5^{\circ}$ (b) $4.0^{\circ}$ (c) $15.0^{\circ}$. 


\section{Conclusions}

This paper reports part of several preliminary studies of the Underwater Drones Group of the Università degli Studi "Roma Tre" Science Department and follows the route traced on several conference papers presented at the IEEE International Workshop on Metrology for the Sea (MetroSea); this part is dedicated to the design and engineering study of the part relating to the UAV buoyancy.

This paper highlights the large series of considerations and structural dimensions, going down in great detail, of the Underwater Glider Mk. III that is currently in an advanced development phase. The real novelties of this work are highlighted in the development due to two strong constraints that our group inserted during the design of this AUV: the first is to evaluate the project always under the most conservative (pessimistic) operating conditions; the second is to evaluate how any changes made to the subsystem in development (in our case the buoyancy s/s) is reflected (and forced) on all the other parts (or subsystems). All the results both from the partial simulations and from the construction and testing of subsystems will then be used in the operating vehicle.

The first section is dedicated to the design and engineering study of the part relating to the UAV buoyancy. In the first section, the architecture, the internal arrangement of the sub glider, the type of mission profile and the maximum requirements for the performances are broadly described. In the second part, the buoyancy system is described from an engineering-construction point of view: the solutions developed and implemented in a working prototype were illustrated.

The last part describes the mathematical requirements for sizing the vehicle. Firstly, the static requirements that are used to determine the mechanical and dimensional sizing of the buoyancy engine are examined. Then the dynamic stability (on the vertical plane) of the vehicle is analysed: this quantifies the forces involved during the "glide". The trajectory is analysed to decide the attitude and the angle of attack: the latter is necessary, in stationary conditions, to determine the work point of the profile or the position of the profile in the diagram " $\mathrm{Cl}$ vs. Alpha". In order to have a constant attitude, it is necessary to balance the moments in the vertical plane so that, once the wing profile is "started" and in progressive acceleration (i.e., while is nearly to reach the terminal velocity) the pitch up effects must be compensated by the movement of the centre of gravity. An evaluation of the uncertainty in the depth control is also provided.

Lastly, a simplified simulation is introduced in order to observe the hydrodynamic behaviour of the fuselage (limited to the profile) and of the aerofoil at different angles of attack, to highlight the stall characteristics.

Author Contributions: The authors have made an equal contribution in all the sections of this article.

Funding: This research received no external funding.

Conflicts of Interest: The authors declare no conflict of interest.

\section{References}

1. Wood, S. Autonomous underwater gliders. In Underwater Vehicles; Chapter 26; Inzartsev, A.V., Ed.; In-Tech: Vienna, Austria, 2009; pp. 499-524.

2. Kayton, M.; Fried, W.R. Avionics Navigation Systems; Wiley: New York, NY, USA, 2007; ISBN 9780471547952.

3. Jenkins, S.A.; Humphreys, D.E.; Sherman, J.; Osse, J.; Jones, C.; Leonard, N.; Graver, J.; Bachmayer, R.; Clem, T.; Carroll, P.; et al. Underwater Glider System Study; Technical Report No. 53; Scripps Institution of Oceanography: San Diego, CA, USA, May 2003.

4. Graver, J.G. Underwater Gliders: Dynamics, Control and Design. Ph.D. Thesis, Princeton University, Princeton, NJ, USA, 2005.

5. Kan, L.; Zhang, Y.; Fan, H.; Yang, W.; Chen, Z. MATLAB-Based simulation of buoyancy-driven underwater glider motion. J. Ocean Univ. Chin. 2007, 7, 113-118. [CrossRef]

6. Woolsey, C.A.; Leonard, N.E. Stabilizing underwater vehicle motion using internal rotors. Automatica 2002, 38, 2053. [CrossRef] 
7. Jekeli, C. Inertial Navigation Systems with Geodetic Applications; Walter de Gruyter Berlin: New York, NY, USA, 2001.

8. Smith, R.N.; Chao, Y.; Jones, B.H.; Caron, D.A.; Li, P.; Sukhatme, G.S. Trajectory Design for Autonomous Underwater Vehicles based on Ocean Model Predictions for Feature Tracking. In Field and Service Robotics; Springer: Berlin/Heidelberg, Germany, 2010; pp. 263-273, 2009.

9. Mitchell, B.; Wilkening, E.; Mahmoudian, N. Low cost underwater gliders for littoral marine research. In Proceedings of the American Control Conference (ACC), Seattle, WA, USA, 17-19 June 2013; pp. 1412-1417.

10. Meyer, D. Glider Technology for Ocean Observations: A Review. Ocean Sci. Discuss. 2016, $2016,1-26$. [CrossRef]

11. Davis, R.E.; Eriksen, C.C.; Jones, C.P. Autonomous buoyancy-driven underwater gliders. In Technology and Applications of Autonomous Underwater Vehicles; Griffiths, G., Ed.; Taylor \& Francis: London, UK, 2002; pp. 37-58.

12. Wang, C.; Zhang, Z.; Gu, J.; Liu, J.; Miao, T. Design and Hydrodynamic Performance Analysis of Underwater Glider Model. In Proceedings of the 2012 International Conference on Computer Distributed Control and Intelligent Environmental Monitoring (CDCIEM), Hunan, China, 5-6 March 2012; pp. 225-227. [CrossRef]

13. De Francesco, E.; De Francesco, E.; De Francesco, R.; Leccese, F.; Cagnetti, M. A proposal to update LSA databases for an operational availability based on autonomic logistic. In Proceedings of the 2nd IEEE International Workshop on Metrology for Aerospace, MetroAeroSpace, Benevento, Italy, 4-5 June 2015; pp. 38-43. [CrossRef]

14. Eriksen, C.C.; Osse, T.J.; Light, R.D.; Wen, T.; Lehman, T.W.; Sabin, P.L.; Ballard, J.W.; Chiodi, A.M. Seaglider: A longrange autonomous underwater vehicle for oceanographic research. IEEE J Oceanic Eng. 2001, 26, 424-436. [CrossRef]

15. Rudnick, D.L.; Eriksen, C.C.; Fratantoni, D.M.; Perry, M.J. Underwater Gliders for Ocean Research. Mar. Technol. Soc. J. 2004, 38, 1.

16. Austin, R. Unmanned Aircraft Systems; Wiley: Hoboken, NJ, USA, 2010.

17. Graver, J.G.; Liu, J.; Woolsey, C.; Leonard, N.E. Design and Analysis of an Underwater Vehicle for Controlled Gliding. In Proceedings of the Conference on Information Sciences and Systems (CISS), Princeton, NJ, USA, 2-5 July 1998.

18. Leccese, F.; Cagnetti, M.; Giarnetti, S.; Petritoli, E.; Luisetto, I.; Tuti, S.; Đurović-Pejčev, R.; Đorđević, T.; Tomašević, A.; Bursić, V.; et al. A Simple Takagi-Sugeno Fuzzy Modelling Case Study for an Underwater Glider Control System. In Proceedings of the 2018 IEEE International Workshop on Metrology for the Sea; Learning to Measure Sea Health Parameters (MetroSea), Bari, Italy, 8-10 October 2018; pp. 262-267. [CrossRef]

19. Teledyne Webb Research. Slocum Electric Glider. Available online: http://www.webbresearch.com/ (accessed on 1 February 2019).

20. Wood, S. State of Technology in Autonomous Underwater Gliders. Mar. Technol. Soc. J. 2013, 47, 5. [CrossRef]

21. Waldmann, C.; Kausche, A.; Iversen, M. MOTH-An underwater glider design study carried out as part of the HGF alliance ROBEX. In Proceedings of the 2014 IEEE/OES Autonomous Underwater Vehicles (AUV), Oxford, UK, 25-29 July 2014; pp. 1-3. [CrossRef]

22. Davis, R.E.; Webb, D.C.; Regier, A.; Dufour, J. The Autonomous Lagrangian Circulation Explorer (ALACE). J. Atmos. Oceanic Technol. 1992, 9, 264-285. [CrossRef]

23. Seo, D.C.; Gyungnam, J.; Choi, H.S. Pitching control simulation of an underwater glider using CFD analysis. In Proceedings of the Oceans-MTS/IEEE Kobe Techno-Ocean, Kobe, Japan, 8-11 April 2008; pp. 1-5.

24. Evans, C.D.; Riggins, R. The Design and Analysis of Integrated Navigation Systems Using Real INS and GPS Data. In Proceedings of the IEEE 1995 National Aerospace and Electronics Conference, Dayton, OH, USA, 22-26 May 1995.

25. Yu, J.; Zhang, F.; Zhang, A.; Jin, W.; Tian, Y. Motion Parameter Optimization and Sensor Scheduling for the Sea-Wing Underwater Glider. IEEE J. Oceanic Eng. 2013, 38, 243-254. [CrossRef]

26. Hussain, N.A.A.; Arshad, M.R.; Mohd-Mokhtar, R. Modeling and Identification of an Underwater Glider. In Proceedings of the 2010 International Symposium on Robotics and Intelligent Sensors (IRIS2010), Nagoya, Japan, 8-11 March 2010.

27. Bohenek, B.J. The Enhanced Performance of an Integrate Navigation System. In A Highly Dynamic Environment; Air Force Institute of Technology: Dayton, OH, USA, 1994. 
28. Beard, R.W.; McLain, T.W. Small Unmanned Aircraft-Theory and Practice; Princeton University Press: Princeton, NJ, USA, 2012.

29. Petritoli, E.; Leccese, F.; Ciani, L. Reliability assessment of UAV systems. In Proceedings of the 4th IEEE International Workshop on Metrology for AeroSpace (MetroAeroSpace), Padua, Italy, 21-23 June 2017; pp. 266-270.

30. Watts, A.C.; Ambrosia, V.G.; Hinkley, E.A. Unmanned Aircraft Systems in Remote Sensing and Scientific Research: Classification and Considerations of Use. Remote Sens. 2012, 4, 1671-1692. [CrossRef]

31. Petritoli, E.; Leccese, F. Improvement of altitude precision in indoor and urban canyon navigation for small flying vehicles. In Proceedings of the 2nd IEEE International Workshop on Metrology for Aerospace (MetroAeroSpace 2015), Benevento, Italy, 4-5 June 2015; pp. 56-60. [CrossRef]

32. Andrade-Bustos, I.; Salgado-Jiménez, T.; García-Valdovinos, L.G.; Bandala-Sánchez, M. Stable Sliding PD Control for underwater gliders: Experimental results. In Proceedings of the Oceans 2016 MTS/IEEE Monterey, Monterey, CA, USA, 19-23 September 2016; pp. 1-7.

33. Pereira, A.; Heidarsson, H.; Caron, D.A.; Jones, B.H.; Sukhatme, G.S. A communication framework for the cost-effective operation of slocum gliders in coastal regions. In Proceedings of the 7 th International Conference on Field and Service Robotics, Cambridge, MA, USA, 14-16 July 2009; pp. 1-10.

34. Skibski, C.E. Design of an Autonomous Underwater Glider focusing on External Wing Control Surfaces and Sensor Integration. Bachelor's Thesis, Florida Institute of Technology, Melbourne, FL, USA, 2009.

35. Isa, K.; Arshad, M.R. An analysis of homeostatic motion control system for a hybrid-driven underwater glider. In Proceedings of the 2013 IEEE/ASME International Conference on Advanced Intelligent Mechatronics (AIM), Wollongong, Australia, 9-12 July 2013; pp. 1570-1575.

36. Küchemann, D. The Aerodynamic Design of Aircraft; Pergamon international library of science, technology, engineering, and social studie; Pergamon Press: Oxford, UK, 1978.

37. Parthasarathy, G.; Sree, D.S.; Manasa, B.L. Design Mathematical Modeling and Analysis of Underwater Glider. Int. J. Sci. Res. 2015, 4, 711-714.

38. Song, D.L.; Yao, L.L.; Wang, Z.Y.; Han, L. Pitching Angle Control Method of Underwater Glider Based on Motion Compensation. In Proceedings of the 2015 International Conference on Computational Intelligence and Communication Networks (CICN), Jabalpur, India, 12-14 December 2015; pp. 1548-1551.

39. Smith, R.N.; Schwager, M.; Smith, S.L.; Rus, D.; Sukhatme, G.S. Persistent Ocean Monitoring with Underwater Gliders Towards Accurate Reconstruction of Dynamic Ocean Processes. In Proceedings of the 2011 IEEE International Conference Robotics and Automation (ICRA), Shanghai, China, 9-13 May 2011; pp. 1517-1524.

40. Techy, L.; Tomokiyo, R.; Quenzer, J.; Beauchamp, T.; Morgansen, K. Full Scale Wind Tunnel Study of the Seaglider Underwater Glider; UWAA Technical Report UWAATR-2010-0002; University of Washington: Seattle, WA, USA, September 2010.

41. Wilcox, J.S.; Bellingham, J.G.; Zhang, Y.; Baggeroer, A.B. Performance metrics for oceanographic surveys with autonomous underwater vehicles. IEEE J Oceanic Eng. 2001, 26, 711-725. [CrossRef]

42. Petritoli, E.; Giagnacovo, T.; Leccese, F. Lightweight GNSS/IRS integrated navigation system for UAV vehicles. In Proceedings of the 2014 IEEE International Workshop on Metrology for Aerospace (MetroAeroSpace), Benevento Italy, 29-30 June 2014; pp. 56-61. [CrossRef]

43. Webb, D.C.; Simonetti, P.J.; Jones, C.P. SLOCUM: An underwater glider propelled by environmental energy. IEEE J Oceanic Eng. 2001, 26, 447-452. [CrossRef]

44. Stommel, H. The Slocum Mission. Oceanography 1989, 2, 22-25. [CrossRef]

45. Sherman, J.; Davis, R.E.; Owens, W.B.; Valdes, J. The autonomous underwater glider "Spray". IEEE J Oceanic Eng. 2001, 26, 437-446. [CrossRef]

46. Titterton, D.; Weston, J. Strapdown Inertial Navigation Technology, 2nd ed.; The Institution of Electrical Engineers and The American Institute of Aeronautics and Astronautics: Reston, VA, USA, 2004.

47. Jun, B.H.; Park, J.Y.; Lee, F.Y.; Lee, P.M.; Lee, C.M.; Kim, K.; Lim, Y.K.; Oh, J.H. Development of the AUV 'ISiMI' and free running test in an ocean engineering basin. Ocean Eng. 2009, 36, 1. [CrossRef]

48. Leonard, N.E.; Graver, J.G. Model-Based feedback control of autonomous underwater gliders. IEEE J. Ocean Eng. 2001, 26, 4. [CrossRef]

49. Arima, M.; Ichihashi, N.; Ikebuchi, T. Motion characteristics of an underwater glider with independently controllable main wings. In Proceedings of the OCEANS 2008-MTS/IEEE Kobe Techno-Ocean, Kobe, Japan, 8-11 April 2008; pp. 1-7. 
50. Roger, E.O.; Genderson, J.G.; Smith, W.S.; Denny, G.; Farley, P.J. Underwater acoustic glider. In Proceedings of the IEEE International Geoscience and Remote Sensing Symposium, Anchorage, AK, USA, 20-24 September 2004; pp. 2241-2244.

51. Woithe, H.C.; Kremer, U. A programming architecture for smart autonomous underwater vehicles. In Proceedings of the IEEE/RSJ International Conference on Intelligent Robots and Systems 2009_IROS 2009, St. Louis, MI, USA, 11-15 October 2009; pp. 4433-4438.

52. Woithe, H.C.; Tilkidjieva, D.; Kremer, U. Towards a Resource-Aware Programming Architecture for Smart Autonomous Underwater Vehicles; Technical Report, DCS-TR-637; Rutgers University: New Brunswick, NJ, USA, 2008.

53. Lennart, L. System Identification Theory for the User, 2nd ed.; Prentice Hall: Upper Saddle River, NJ, USA, 1999.

54. Petritoli, E.; Leccese, F. High accuracy attitude and navigation system for an autonomous underwater vehicle (AUV). Acta IMEKO 2018, 7, 3-9. [CrossRef]

55. Petritoli, E.; Leccese, F. A high accuracy navigation system for a tailless underwater glider. In Proceedings of the IMEKO TC19 Workshop on Metrology for the Sea, MetroSea 2017: Learning to Measure Sea Health Parameters, Naples, Italy, 11-13 October 2017; pp. 127-132.

56. Petritoli, E.; Leccese, F. A high accuracy attitude system for a tailless underwater glider. In Proceedings of the IMEKO TC19 Workshop on Metrology for the Sea, MetroSea 2017: Learning to Measure Sea Health Parameters, Naples, Italy, 11-13 October 2017; pp. 7-12.

57. DSIAC. Reliability of UAVs and Drones. Available online: https://www.dsiac.org/resources/journals/dsiac/ spring-2017-volume-4-number-2/reliability-uavs-and-drones (accessed on 28 February 2019).

58. Etkin, B. Dynamic of Flight; John Wiley and Sons: Hoboken, NJ, USA, 1959.

59. Tan, X.; Kim, D.; Usher, N.; Laboy, D.; Jackson, J.; Kapetanovic, A.; Rapai, J.; Sabadus, B.; Zhou, X. An Autonomous Robotic Fish for Mobile Sensing. In Proceedings of the 2006 IEEE/RSJ International Conference on Intelligent Robots and Systems, Beijing, China, 9-15 October 2006; pp. 5424-5429.

60. Smith, R.N.; Pereira, A.; Chao, Y.; Li, P.P.; Caron, D.A.; Jones, B.H.; Sukhatme, G.S. Autonomous Underwater Vehicle trajectory design coupled with predictive ocean models: A case study. In Proceedings of the 2010 IEEE International Conference on Robotics and Automation (ICRA), Anchorage, AK, USA, 4-8 May 2010; pp. 4770-4777.

61. Petritoli, E.; Leccese, F.; Cagnetti, M. A High Accuracy Buoyancy System Control for an Underwater Glider. In Proceedings of the 2018 IEEE International Workshop on Metrology for the Sea; Learning to Measure Sea Health Parameters (MetroSea), Bari, Italy, 8-10 October 2018; pp. 257-261. [CrossRef]

62. Techy, L.; Kristi Morganseny, A.; Woolseyz, C.A. Long-baseline acoustic localization of the Seaglider underwater glider. In Proceedings of the American Control Conference (ACC) 2011, San Francisco, CA, USA, 29 June-1 July 2011; pp. 3990-3995.

63. Hussain, N.A.A.; Ali, S.S.A.; Saad, M.N.M.; Nordin, N. Underactuated nonlinear adaptive control approach using U-model for multivariable underwater glider control parameters. In Proceedings of the 2016 IEEE International Conference on Underwater System Technology: Theory and Applications (USYS), Penang, Malaysia, 13-14 December 2016; pp. 19-25. [CrossRef]

64. Yu, P.; Zhao, Y.; Wang, T.; Zhou, H.; Su, S.; Zhen, C. Steady-state spiral motion simulation and turning speed analysis of an underwater glider. In Proceedings of the 2017 th International Conference on Information Cybernetics and Computational Social Systems (ICCSS), Dalian, China, 24-26 July 2017; pp. 372-377.

65. Bloch, T.; Krishnaprasad, P.S.; Leonard, N.; Murray, R. Jerrold Eldon Marsden [Obituaries]. Control Syst. IEEE 2011, 31, 105-108.

66. Williams, C.D. AUV systems research at the NRC-IOT: An update. In Proceedings of the Underwater Technology 2004-UT '04. 2004 International Symposium on, Taipei, Taiwan, 20-23 April 2004; pp. 59-73.

67. Jing, D.; Haifeng, W. System health management for unmanned aerial vehicle: conception, state-of-art, framework and challenge. In Proceedings of the Electronic Measurement \& Instruments (ICEMI). In Proceedings of the 2013 IEEE 11th International Conference, Harbin, China, 16-19 August 2013; Volume 2, pp. 859-863.

68. Javafoil-Analysys of Airfolis. Available online: https://www.mh-aerotools.de/airfoils/javafoil.htm (accessed on 15 February 2019).

69. Vogeltanz, T. A Survey of Free Software for the Design, Analysis, Modelling, and Simulation of an Unmanned Aerial Vehicle. Arch. Comput. Meth. Eng. 2016, 23, 449. [CrossRef] 
70. Vogeltanz, T.; Jašek, R. Free software for the modelling and simulation of a mini-UAV. In Proceedings of the Mathematics and Computers in Science and Industry, Varna, Bulgaria, 13-15 September 2014; pp. $210-215$.

71. Jodeh, N.; Blue, P.; Waldron, A. Development of small unmanned aerial vehicle research platform: Modeling and simulating with flight test validation. In Proceedings of the AIAA Modeling and Simulation Technologies Conference and Exhibit, Keystone, CO, USA, 21-24 August 2006; p. 6261.

72. Mueller, T.J.; DeLaurier, J.D. Aerodynamics of small vehicles. Annual review of fluid mechanics 2003, 35, 89-111. [CrossRef]

73. Fabiani, P.; Fuertes, V.; Piquereau, A.; Mampey, R.; Teichteil-Königsbuch, F. Autonomous flight and navigation of VTOL UAVs: From autonomy demonstrations to out-of-sight flights. Aerosp. Sci. Technol. 2007, 11, 183-193. [CrossRef]

74. Wu, N.; Wu, C.; Ge, T.; Yang, D.; Yang, R. Pitch Channel Control of a REMUS AUV with Input Saturation and Coupling Disturbances. Appl. Sci. 2018, 8, 253. [CrossRef]

75. Hahn, A. Vehicle sketch pad: A parametric geometry modeller for conceptual aircraft design. In Proceedings of the 48th AIAA Aerospace Sciences Meeting Including the New Horizons Forum and Aerospace Exposition, Orlando, FL, USA, 4-7 January 2010; p. 657. [CrossRef]

76. Wang, T.; Wu, C.; Wang, J.; Ge, T. Modeling and Control of Negative-Buoyancy Tri-Tilt-Rotor Autonomous Underwater Vehicles Based on Immersion and Invariance Methodology. Appl. Sci. 2018, 8, 1150. [CrossRef]

77. Boussalis, H.; Valavanis, K.; Guillaume, D.; Pena, F.; Diaz, E.U.; \& Alvarenga, J. Control of a simulated wing structure with multiple segmented control surfaces. In Proceedings of the 2013 21st Mediterranean Conference IEEE Control \& Automation (MED), Crete, Greece, 25-28 June 2013; pp. 501-506.

78. Wang, T.; Wang, J.; Wu, C.; Zhao, M.; Ge, T. Disturbance-Rejection Control for the Hover and Transition Modes of a Negative-Buoyancy Quad Tilt-Rotor Autonomous Underwater Vehicle. Appl. Sci. 2018, 8, 2459. [CrossRef]

(C) 2019 by the authors. Licensee MDPI, Basel, Switzerland. This article is an open access article distributed under the terms and conditions of the Creative Commons Attribution (CC BY) license (http://creativecommons.org/licenses/by/4.0/). 